\title{
Thirty-day results from prospective multi-specialty evaluation of carotid artery stenting using the CGuard MicroNet-covered Embolic Prevention System in real-world multicentre clinical practice: the IRON-Guard study
}

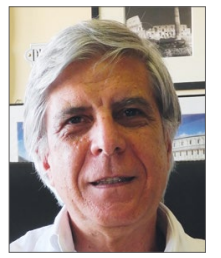

Francesco Speziale $^{1}, \mathrm{MD}$; Laura Capoccia ${ }^{2 *}, \mathrm{MD}$; Pasqualino Sirignano ${ }^{1}, \mathrm{MD}$; Wassim Mansour ${ }^{1}$, MD; Chiara Pranteda ${ }^{1}$, MD; Renato Casana ${ }^{2}$, MD; Carlo Setacci ${ }^{3}$, MD; Federico Accrocca ${ }^{4}, \mathrm{MD}$; Domenico Alberti ${ }^{5}, \mathrm{MD}$; Gianmarco de Donato ${ }^{3}, \mathrm{MD}$; Michelangelo Ferri ${ }^{6}, \mathrm{MD}$; Andrea Gaggiano ${ }^{7}, \mathrm{MD}$; Giuseppe Galzerano ${ }^{3}, \mathrm{MD}$; Arnaldo Ippoliti ${ }^{8}, \mathrm{MD}$; Nicola Mangialardi 9 , MD; Giovanni Pratesi ${ }^{8}, \mathrm{MD}$; Sonia Ronchey ${ }^{9}, \mathrm{MD}$; Maria Antonella Ruffino ${ }^{10}$, MD; Andrea Siani ${ }^{4}$, MD; Angelo Spinazzola ${ }^{11}$, MD; Massimo Sponza ${ }^{12}$, MD

\section{Vascular and Endovascular Surgery Division, Department of Surgery "Paride Stefanini", Policlinico Umberto I, "Sapienza" University of Rome, Rome, Italy; 2. Vascular and Endovascular Surgery Unit, Istituto Auxologico IRCCS, Milan, Italy; \\ 3. Vascular and Endovascular Surgery Division, Department of Medicine, Surgery and Neurological Sciences, Policlinico S. Maria alle Scotte, University of Siena, Siena, Italy; 4. Unit of Vascular and Endovascular Surgery, "San Paolo" Hospital, Civitavecchia, Italy; 5. Vascular and Endovascular Surgery Unit, "Belcolle" Hospital, Viterbo, Italy; 6. Vascular and Endovascular Surgery Unit, Mauriziano Umberto I Hospital, Turin, Italy; 7. Vascular and Endovascular Surgery Unit, "Cardinal Massaia" Hospital, Asti, Italy; 8. Vascular and Endovascular Surgery Unit, "Tor Vergata" University of Rome, Rome, Italy; 9. Vascular and Endovascular Surgery Unit, S. Filippo Neri Hospital, Rome, Italy; 10. Vascular and Interventional Radiology, Città della Salute Hospital, Turin, Italy; 11. Vascular and Interventional Radiology, Crema City Hospital, Crema, Italy; 12. Vascular and Interventional Radiology, "Santa Maria della Misericordia" Hospital, Udine, Italy}

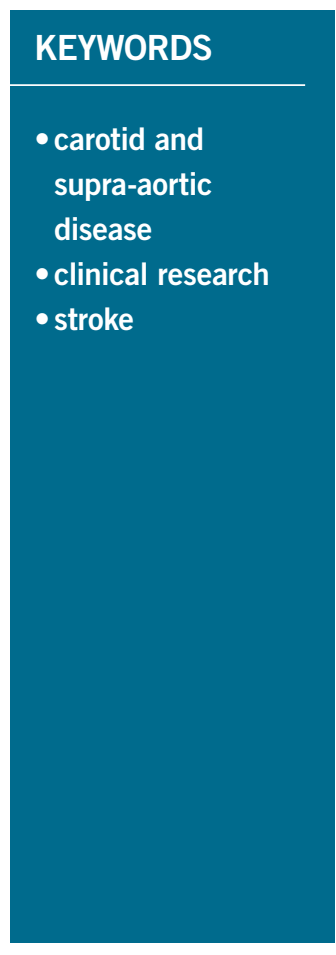

\begin{abstract}
Aims: The aim of the present study was to evaluate periprocedural and 30-day outcomes in a prospective series of patients treated with the CGuard Embolic Prevention System (EPS).

Methods and results: From April 2015 to June 2016, a physician-initiated prospective multicentre study was performed in 200 consecutive patients admitted for protected carotid artery stenting (CAS) and treated using the CGuard EPS in twelve vascular centres. Outcome measures were: technical success, periprocedural (0-24 hours) and post-procedural (24 hours-30 days) major and minor strokes, death, acute myocardial infarction (AMI), transient ischaemic attack (TIA), and external carotid occlusion. In three centres, consecutive diffusion-weighted magnetic resonance cerebral imaging (DW-MRI) was performed $\leq 72$ hours prior to and within 72 hours after the intervention. A distal embolic protection device was employed in 182 patients (91\%). Technical success was $100 \%$. No death, AMI or major stroke occurred periprocedurally. There were two TIAs and five periprocedural minor strokes $(2.5 \%)$, including one thrombosis solved by surgery. In the remaining patients (199/200; 99.5\%) one-month follow-up duplex ultrasound revealed optimal technical results. Post-procedural clinical follow-up was uneventful. No external carotid artery occlusion occurred. New post-procedural DW-MRI lesions were detected in 12 patients out of 61 (19.6\%), including bilateral in five $(8.2 \%)$ and isolated ipsilateral in six $(9.8 \%)$, whereas one patient $(1.6 \%)$ had contralateral only lesions.
\end{abstract}

Conclusions: Multicentre multi-specialty use of the CGuard EPS in routine clinical practice was associated with no major periprocedural neurologic complications and a total elimination of post-procedural neurologic complications by 30 days.

\footnotetext{
*Corresponding author: Vascular and Endovascular Surgery Division, Department of Surgery "Paride Stefanini”, Policlinico Umberto I, "Sapienza” University of Rome, 155, Viale del Policlinico,00161 Rome, Italy.E-mail: laura.capoccia@uniromal.it
} 


\section{Abbreviations}

$\begin{array}{ll}\text { AMI } & \text { acute myocardial infarction } \\ \text { atm } & \text { atmospheres } \\ \text { CAS } & \text { carotid artery stenting } \\ \text { CCA } & \text { common carotid artery } \\ \text { CEA } & \text { carotid endarterectomy } \\ \text { CLL } & \text { centre lumen line } \\ \text { CTA } & \text { computed tomographic angiography } \\ \text { DUS } & \text { duplex ultrasound } \\ \text { DW-MRI } & \text { diffusion-weighted magnetic resonance imaging } \\ \text { EPS } & \text { embolic prevention system } \\ \text { ICA } & \text { internal carotid artery } \\ \text { IFU } & \text { instructions for use } \\ \text { MRI } & \text { magnetic resonance imaging } \\ \text { NIHSS } & \text { National Institutes of Health Stroke Scale } \\ \text { TIA } & \text { transient ischaemic attack }\end{array}$

\section{Introduction}

Brain embolism remains the Achilles' heel of carotid revascularisation procedures. That risk is increased in symptomatic plaques, and is considered to be maximal during the procedural phase of both open and endovascular procedures ${ }^{1}$. As a rule, during carotid endarterectomy (CEA), some adjunct techniques to reduce embolism are used, such as early clamping of the internal carotid artery ${ }^{2}$, accurate dissection of the carotid bulb, and early administration of heparin. Similarly, during carotid artery stenting (CAS), specific solutions have been developed and are currently employed in order to reduce macro and micro brain emboli from plaque as well as from access vessels. These techniques include the use of proximal or distal embolic protection devices (EPD) ${ }^{3}$, careful manipulation of the aortic arch or, alternatively, the use of cervical access ${ }^{4}$. Indeed, during CAS, cerebral embolisation may occur during the target artery cannulation, lesion wiring, predilatation, stent placement and deployment, and stent post-dilatation occurs 5 . Moreover, the risk of embolism is not limited to the procedure time but, with conventional carotid stents, it extends to a post-procedural period of $\approx 30$ days ("stent healing") ${ }^{6,7}$, when the interaction between stent struts and plaque surface and composition is active during endothelialisation. To overcome the risk of plaque prolapse and persistent microembolism seen after CAS using conventional carotid stents ${ }^{8-11}$, a new generation of mesh-covered stents has been developed and introduced into clinical use ${ }^{12,13}$. In April 2015, a physician-initiated prospective multicentre registry of carotid stenting with the new CGuard ${ }^{\mathrm{TM}}$ MicroNet-covered Embolic Prevention System (InspireMD, Boston, MA, USA) was started in Italy ${ }^{14}$. The aim of the present study was to evaluate periprocedural ( $\leq 24$ hours) and post-procedural (up to 30 days) outcomes in a prospective multicentre series of consecutive patients submitted for protected CAS with CGuard stent implantation from April 2015 to June 2016.

\section{Editorial, see page 1629}

\section{Materials and methods POPULATION}

Twelve experienced vascular centres prospectively enrolled consecutive patients submitted for CAS to be treated with the CGuard stent. Inclusion criteria for enrolment in the registry were: symptomatic (index event in the previous six months) $\geq 50 \%$ and asymptomatic $\geq 70 \%$ (NASCET criteria $^{15}$ ) carotid stenosis; target lesion at distal common carotid artery (CCA), internal carotid artery (ICA), or carotid bifurcation; arterial segment to be stented presenting with a native diameter between 4 and $9 \mathrm{~mm}$; life expectancy $>12$ months from the date of the index procedure; willingness and capacity to comply with enrolment and follow-up requirements. Exclusion criteria for enrolment were: clinical condition preventing endovascular therapy; uncorrectable bleeding disorders; history of previous lifethreatening contrast media reaction; known allergy or unwillingness or incapacity to comply with heparin, aspirin, or other anticoagulant/antiplatelet therapies; known allergy to nickel/titanium; disallowance to take blood transfusion; evolving stroke or intracranial haemorrhage; previous intracranial haemorrhage or brain surgery within the past 12 months; history of intracerebral aneurysm or arteriovenous malformation; severe vascular tortuosity or anatomy precluding safe introduction of a guide catheter sheath, EPD, or stent; common carotid artery ostial lesion (unless treated simultaneously); occlusion of the target vessel; intraluminal thrombosis; previous stented target carotid artery. All consecutive patients were registered in a logbook that included 208 patients. Eight patients (3.5\%) could not be enrolled due to the presence of $\geq 1$ exclusion criterion: in detail, three patients presented with known allergy to iodinated contrast media, three patients with restenosis, one patient had previous cerebral haemorrhage, and one patient was excluded because of severe tortuosity of target access. The study conformed to the Declaration of Helsinki. All patients enrolled in the study gave their informed written consent to be submitted for CAS and to be included in the present study.

\section{DEFINITIONS}

Presence of symptoms, transient ischaemic attack (TIA), minor and major strokes were classified according to current definitions $^{16}$. Carotid plaques were categorised as hyperechoic ${ }^{17}$, isoechoic $^{17}$, hypo-anechoic ${ }^{17}$, or dishomogeneous ${ }^{17}$, ulcerated or thin fibrous cap ${ }^{18,19}$. Aortic arch was classified as I, II, or III type, or bovine ${ }^{20}$; thrombus and calcium presence was divided into $<50 \%$ or $\geq 50 \%$ of the entire vessel circumference assessed on centre lumen line (CLL) reconstruction; vascular tortuosity was categorised into none $\left(0-30^{\circ}\right)$, low $\left(30^{\circ}-60^{\circ}\right)$, moderate $\left(60^{\circ}-90^{\circ}\right)$, or severe $\left(>90^{\circ}\right)^{21}$. Technical success was defined as absence of any device-related malfunctions. Procedural success was defined as complete plaque coverage as per intention to treat, without any target vessel occlusion, thrombosis, dissection, residual stenosis $\geq 30 \%$, or intracranial vessel occlusion.

\section{STENTING PROCEDURE}

Preprocedural work-up included: complete medical history and physical examination; carotid duplex ultrasound (DUS); arch, supra-aortic vessels and cranial computed tomographic angiography (CTA) or magnetic resonance imaging (MRI-ECGgated, steady state free precession); neurological assessment. 
All procedures were performed with EPDs and the CGuard stent according to operator preference and instructions for use (IFU) with systemic heparinisation (70 UI/ $\mathrm{kg}$ ). Preprocedurally and at 30 days, all patients were submitted for carotid DUS. An independent neurologist assessed all patients prior to CAS, before discharge and at one-month follow-up. All patients were placed on dual antiplatelet therapy starting from at least two days before CAS up to at least 30 days post procedure. Lifelong single antiplatelet therapy was prescribed. In three centres with access to diffusion-weighted magnetic resonance brain imaging (DW-MRI), all patients included were submitted to preprocedural and post-procedural (24-72 hours) cerebral DW-MRI in order to detect any new post-procedural brain ischaemic lesions.

Primary endpoints were technical and procedural success, periprocedural (0-30 days) major and minor stroke, death, and TIA rates. Secondary endpoints were acute myocardial infarction (AMI) ${ }^{22}$, and external carotid artery occlusion rates.

\section{STATISTICAL ANALYSIS}

Data on demographic characteristics, preprocedural evaluation, CAS procedure, and post-procedural results and follow-up were entered into a dedicated prospectively compiled database and were analysed as potentially affecting outcomes. Data are reported as numbers and percentages. Statistical analysis was performed with SPSS, Version 22 (IBM Corp., Armonk, NY, USA). Significance was set at $\mathrm{p}<0.05$.

\section{Results}

Two hundred consecutive CAS patients were enrolled per protocol. Demographic and clinical characteristics are listed in Table 1. Symptoms related to carotid plaque were present in $8.5 \%$ of cases: 14 patients had presented a TIA (one month before the procedure in 12 cases, three months before in one case, and four months before in one case), two patients a minor stroke (one month before CAS in one case, and six months before in one case), and one patient a major stroke (six months before CAS). Supra-aortic vessel features are listed in Table 2. Hypo-anechoic and dishomogeneous plaque composition was encountered in $17 \%$ and $15 \%$ of patients, respectively. Unstable plaques (ulcerated or thin fibrous cap) were detected in $15 \%$ of cases. More than $50 \%$ thrombus or calcification

Table 1. Demographic characteristics of patients included in the registry.

\begin{tabular}{|l|c|c|}
\hline \multirow{2}{*}{ Age, years $($ mean \pm SD) } & n & $\%$ \\
\hline Male sex & 132 & 66 \\
\hline Symptoms & 17 & 8.5 \\
\hline Hypertension & 174 & 87 \\
\hline Diabetes & 56 & 28 \\
\hline Hyperlipidaemia & 148 & 74 \\
\hline Coronary artery disease & 68 & 34 \\
\hline Smoking history & 124 & 62 \\
\hline
\end{tabular}

Table 2. Anatomical characteristics of patients included in the registry.

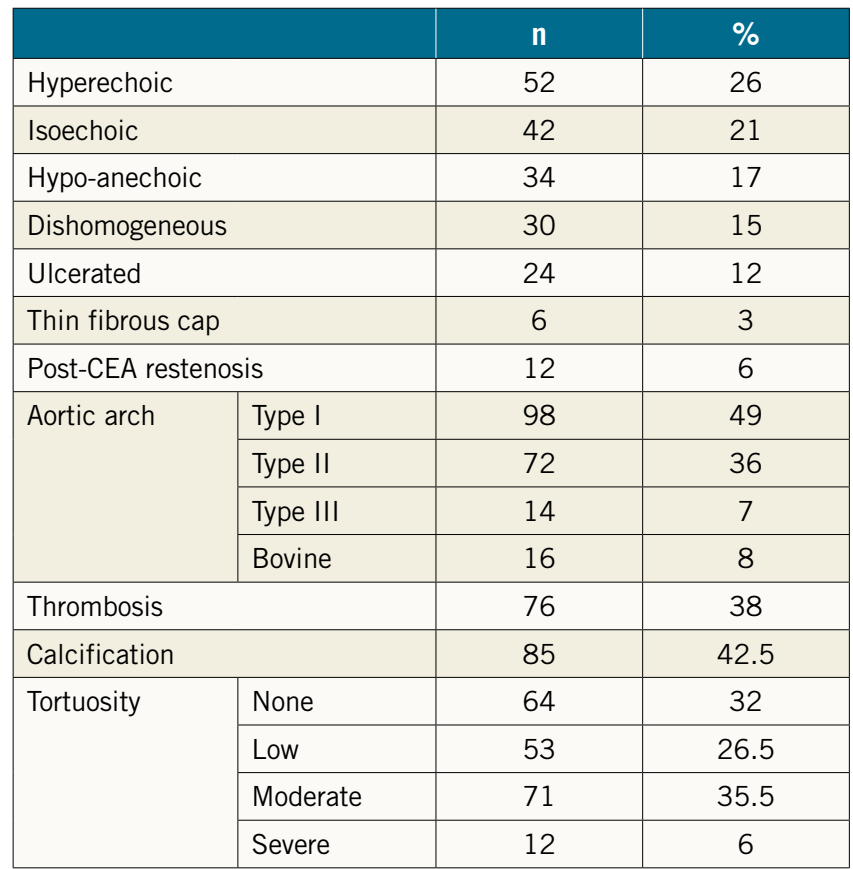

in the access vessels was recognised in $38 \%$ and $42.5 \%$ of cases, respectively, and severe access vessel tortuosity in 6\%. Femoral access was employed in 194 patients (97\%) and radial access in six $(3 \%)$. The embolic protection device used was a distal filter in 182 patients (FilterWire EZTM; Boston Scientific, Marlborough, MA, USA, in 82; Emboshield ${ }^{\mathrm{TM}}$ NAV6; Abbott Vascular, Santa Clara, CA, USA, in 93; Spider FX' ${ }^{\mathrm{TM}}$; ev3, Inc., Plymouth, MN, USA, in 7; 91\%), proximal occlusion with flow reversal in 18 (Mo. Ma; Medtronic, Santa Rosa, CA, USA; 9\%). Predilatation was used in $32 \%$ of cases with a $2.0-3.0 \mathrm{~mm}$ diameter balloon, $8.7 \mathrm{~atm}$ mean pressure (range 4-14 atm) for 6.4 seconds mean time (range $2-30 \mathrm{sec}$ ). Post-dilatation was employed in $86 \%$ of patients with a $5.1 \mathrm{~mm}$ mean balloon diameter (range $4.5-5.5 \mathrm{~mm}$ ), mean pressure of $8.8 \mathrm{~atm}$ (range 4-16 atm) lasting for a mean of 7.6 seconds (range 2-30 sec). Intraprocedural atropine endovenous administration was employed in 153 cases (76.5\%). Mean procedure time was 37.49 minutes (range 9-90 minutes), and mean fluoroscopy time was 12.19 minutes (range 4-30 minutes). Femoral artery haemostasis was obtained by closure device in 138 cases (FemoSeal ${ }^{\mathrm{TM}}$; St. Jude Medical, St. Paul, MN, USA, in 39; AngioSealTM; St. Jude Medical, in 43; Perclose ProGlide; Abbott Vascular, in 56; 69\%). Technical and procedural success was achieved in all 200 patients $(100 \%)$. In one patient, one single stent was unable to cover the whole length of plaque and a second stent was implanted. An independent committee evaluated the adverse events. No death, AMI or major stroke was recorded periprocedurally. There were five (2.5\%) minor strokes, including one minor stroke due to ineffective heparinisation and thrombosis that was resolved by surgery. Two additional TIAs, and two mental confusions were recorded periprocedurally. An independent neurologist in each centre evaluated 
postoperative adverse events. Diagnosis and classification of postprocedural events occurred in all cases in patients treated for asymptomatic stenosis, in two patients by DW-MRI and in the remaining patients by CT scans. Images and clinical data were sent to the centralised independent committee composed of a neurologist, a cardiologist, and a vascular surgeon. One-month DUS follow-up showed good technical results with no external carotid artery occlusion.

\section{DW-MRI MICROEMBOLIC LESION DETECTION}

In the three centres with access to routine DW-MRI imaging, 61 out of 64 patients were submitted for preprocedural ( $\leq 72 \mathrm{hrs}$ ) and post-procedural ( $\leq 72 \mathrm{hrs}$ ) DW-MRI. In three patients DW-MRI could not be performed due to the presence of MRI contraindications. Demographic, clinical and procedural characteristics are reported in Table 3. Vulnerable plaque composition (comprising hypo-anechoic, dishomogeneous, ulcerated, thin fibrous cap patterns) was recorded in 18 patients $(29.5 \%)$. New post-procedural DW-MRI lesions were detected in 12 patients (19.6\%): among them six $(9.8 \%)$ presented with ipsilateral-only and six $(9.8 \%)$ with contralateral or bilateral lesions. Demographic, clinical and procedural characteristics were analysed as potentially affecting the onset of new ischaemic lesions on DW-MRI (Table 3). Filter type was significantly associated with new DW-MRI lesions $(\mathrm{p}=0.005)$ (Table 3); all six patients presenting ipsilateral DW-MRI lesions were submitted for CAS with FilterWire EZ ( $p=0.007)$. No significant association was detected between demographics and supra-aortic vessel features $(p>0.05)$ (Table 3). Among patients presenting postoperative minor neurological complications (five minor strokes, two TIAs, and two mental confusions overall), two had been included in the DW-MRI substudy. One patient with minor stroke due to ineffective heparinisation and thrombosis that was resolved by surgery and one patient with TIA presented ipsilateral multiple brain lesions on DW-MRI. The characteristics of patients presenting new postprocedural microembolic lesions are listed in Table 4.
Table 3. Numbers, percentages, and probability of significant association with new ischaemic lesions on postoperative DW-MRI of demographic, clinical and procedural characteristics in 61 patients.

\begin{tabular}{|c|c|c|c|c|}
\hline & n Tot & $\%$ Tot & n Events & $p$-value \\
\hline Age, years (mean $\pm S D)$ & \multicolumn{2}{|c|}{$72.8 \pm 7.24$} & $73.9 \pm 7.4^{*}$ & 0.59 \\
\hline Male sex & 39 & 63.9 & 7 & 0.447 \\
\hline Symptoms & 7 & 11.4 & 1 & 0.385 \\
\hline Hypertension & 61 & 100 & 12 & - \\
\hline
\end{tabular}

Table 4. Characteristics of patients presenting new postoperative (24/72 hours) DW-MRI microembolic brain lesions.

\begin{tabular}{|c|c|c|c|c|c|c|c|c|c|c|c|}
\hline & Age & Symptoms & Side & $\begin{array}{c}\text { Vulnerable } \\
\text { plaque }\end{array}$ & $\begin{array}{c}\text { Arch } \\
\text { type }\end{array}$ & $\begin{array}{c}\text { Thrombus (1) } \\
\text { and/or calcium (2) }\end{array}$ & Tortuosity & EPD & $\begin{array}{c}\text { Predilatation } \\
\text { atm/sec }\end{array}$ & $\begin{array}{c}\text { Post-dilatation } \\
\text { atm/sec }\end{array}$ & $\begin{array}{c}\text { Side of } \\
\text { microembolism }\end{array}$ \\
\hline 1 & 80 & None & R & Yes & I & 1 & None & FilterWire EZ & - & $14 / 2$ & Contralateral \\
\hline 2 & 71 & None & L & - & I & - & None & FilterWire EZ & $14 / 2$ & $14 / 2$ & Bilateral \\
\hline 3 & 75 & None & L & - & I & 2 & None & Spider & - & $6 / 30$ & Bilateral \\
\hline 4 & 84 & TIA 1 month before & L & Yes & Bovine & 2 & Severe & FilterWire EZ & - & $8 / 15$ & Bilateral \\
\hline 5 & 70 & None & R & - & Bovine & - & None & FilterWire EZ & - & $4 / 10$ & Ipsilateral \\
\hline 6 & 73 & None & R & Yes & II & - & None & FilterWire EZ & - & $4 / 5$ & Ipsilateral \\
\hline 7 & 68 & None & L & - & I & - & Low & FilterWire EZ & - & $4 / 5$ & Ipsilateral \\
\hline 8 & 71 & None & L & - & II & - & Low & Mo.Ma & $4 / 5$ & - & Bilateral \\
\hline 9 & 68 & None & R & - & II & - & None & FilterWire EZ & $4 / 5$ & $4 / 5$ & Ipsilateral \\
\hline 10 & 79 & None & R & - & I & 2 & Moderate & FilterWire EZ & - & $4 / 5$ & Bilateral \\
\hline 11 & 73 & None & R & - & Bovine & 2 & None & FilterWire EZ & $4 / 5$ & $4 / 5$ & Ipsilateral \\
\hline 12 & 75 & None & R & - & II & 2 & None & FilterWire EZ & $4 / 5$ & $4 / 5$ & Ipsilateral \\
\hline
\end{tabular}

atm: atmospheres; DW-MRI: diffusion-weighted magnetic resonance imaging; EPD: embolic protection device; L: left; R: right; Vulnerable plaque: comprising hypo-anechoic, dishomogeneous, ulcerated, and thin fibrous cap plaque composition 


\section{Discussion}

IRON-Guard, the largest multicentre, multi-specialty study to date, comprising cardiologists, radiologists and vascular surgeons, collected data in 200 consecutive CAS patients treated using the novel MicroNet-covered CGuard Embolic Prevention System. It showed no major periprocedural or post-procedural adverse events over the 30-day clinical and neurological follow-up. The number of patients recruited in the study centres varied from four to 41 (median 16.7), and the centres had no prior experience with the new stent system. Nevertheless, all the study centres perform more than 50 CAS per year, as set by an ICCS-SPREAD joint committee in order to offer powerful protection against complications ${ }^{23}$. In the periprocedural period there were five $(2.5 \%)$ minor strokes in relation to the lack of exclusion of high-risk patients $(47 \%$ enrolled had high-risk unstable or thrombus-containing lesions) and the relatively low $(<10 \%)$ proximal EPD use in this study, while at the same time the MicroNet stent coverage protection against cerebral embolisation can function only in the period that follows stent deployment. These results are in line with the 30-day outcomes in recently published studies of mesh-covered carotid stents ${ }^{6,12,13,24}$. The first published prospective study on the use of the CGuard stent, the CARENET (Carotid Embolic Protection Using MicroNet) trial ${ }^{13}$ and the Italian registry of the Roadsaver ${ }^{\mathbb{B}}$ carotid artery stent (Terumo Corp., Tokyo, Japan) ${ }^{12}$, a double layer micromesh stent, have both shown $0 \%$ adverse events at 30 days. In our study we included by protocol both asymptomatic and symptomatic patients, albeit the latter in a small percentage $(8.5 \%)$. Prospective registries on mesh-covered or dual-layer CAS have included higher percentages of symptomatic patients, thus justifying excellent results in more risky patients than in our experience ${ }^{6,7,12,13}$. Nevertheless, in our study $17 \%$ of patients had a hypo-anechoic plaque composition, $15 \%$ a dishomogeneous one, and $17 \%$ presented with an ulcerated surface or a thin fibrous cap, accounting for $47 \%$ of patients with "high risk for CAS" plaque characteristics ${ }^{25}$.

The need to treat high-risk patients presenting with relevant comorbidities eventually preventing CEA, and/or risky plaque characteristics possibly preventing CAS, has prompted the development of new-generation carotid stents. Bosiers et al indicated a higher neurological complication rate in symptomatic patients submitted for CAS with open-cell stents compared to those with a closedcell configuration ${ }^{26}$, and the increased risk of adverse neurologic events with open-cell stents was recently confirmed in the European Registry of Carotid Stenting ${ }^{23}$. Therefore, free-cell area has a predominant role in the possibility of actively capturing plaque debris and preventing plaque prolapse, and the industry has conceived and developed new stents with a high plaque coverage capability. The Roadsaver carotid artery stent system has a dual-layer nitinol design with a cell size of $375-500 \mu \mathrm{m}^{12}$. The carotid stent clinical study for the treatment of carotid artery stenosis in patients at increased risk for events from carotid endarterectomy (SCAFFOLD) trial evaluated the safety and efficacy of a new $500 \mu \mathrm{m}$ cell-size hybrid stent (Gore Carotid Stent; W.L. Gore \& Associates, Inc., Flagstaff, AZ,
USA) in a prospective, multicentre, single-arm study with the primary endpoint of composite major adverse events up to one year post index procedure in patients with increased risk for adverse events related to carotid endarterectomy ${ }^{27}$. Similar to the Gore Carotid Stent, the CGuard Embolic Prevention System is composed of an open-cell nitinol stent, covered by a bio-stable mesh of polyethylene terephthalate (MicroNet) that is joined to the nitinol skeleton at both extremities, and has a pore size of $165 \mu \mathrm{m}$, the smallest one available on the market among all carotid stents. All three stents have been developed in order to reduce the free-cell area appreciably, and preliminary data on the CGuard and Roadsaver stents are encouraging ${ }^{6,12,13}$. However, keeping the pore size to the smallest possible seems relevant, since Rapp et al found that embolic particles with a diameter between 200 and $500 \mu \mathrm{m}$ can induce neuronal injury, while particles of less that $200 \mu \mathrm{m}$ are not responsible for neuronal damage ${ }^{28,29}$. In that respect, the CGuard stent appears to be the only one to satisfy the required dimensions; nevertheless, the CAS potential for causing significant neuronal changes according to free-cell area should be studied in a comparative prospective study including all the various new-generation stents. In the present study, only $19.6 \%$ of patients submitted for DW-MRI presented new embolic ischaemic lesions, in line with recent reports from studies evaluating new-generation CAS devices ${ }^{30}$. Moreover, the time point for DW-MRI performance also seems relevant, since magnetic resonance sensibility to detect ischaemic damages is strictly timedependent. We were able to perform DW-MRI at $<72$ hours postprocedurally, but we were not able to classify exactly our events as intraprocedural or post-procedural. On the other hand, the possibility of embolism from the arch should be properly evaluated, ideally during and after the procedure. This is surely not completely prevented by the intraprocedural use of EPDs, or even the flow-reversal systems with femoral access. Indeed, in our study we found a significant association between FilterWire EZ use and the incidence of new microembolic brain lesions, demonstrating that the majority of events can be considered intraprocedural rather than post-procedural or "off-table". In that respect, the use of flow-reversal protection systems may be considered safer during the procedure ${ }^{31}$, while the use of cervical systems might be considered protective from intraprocedural and post-procedural possible arch plaque debris detachments. Because of the absence of external funding we could not perform DW-MRI imaging at 30 days after CAS (the CARENET trial reported all brain lesions but one "healed" at 30-day DWI) ${ }^{13}$; therefore, we could not properly check for "healed lesions" at that time point. In the present study, which collected detailed intraprocedural data from 12 centres, a huge variability in indication for, time and pressure of dilatation was found, probably reflecting what is common experience in a real-world setting. Therefore, in our study we collected a time range of between 2 and 30 seconds of balloon inflation and a range between 4 and 14 or 16 atm for pressure in both predilatation and post-dilatation. Of course, pressure exerted on the plaque was extremely variable, and it can be speculated that different forces can act differently on the plaque surface and composition, especially for predilation that was reported in the present 
series in $32 \%$ of patients. Although the DW-MRI subgroup in our study includes the largest series of routine per-protocol DW-MRI imaging in consecutive CAS using a dual-layer stent to date, it is still not large enough to detect the impact of predilatation on cerebral embolisation risk prior to CGuard MicroNet-established prevention.

\section{Limitations}

Our study has the limitation of being a single-arm study with no control group; nevertheless, it reflects a real-world experience, given that it collected data from 12 experienced vascular centres performing CAS. A longer follow-up is needed in order to confirm the long-term durability of carotid revascularisation using the new MicroNet-covered CGuard stent. Moreover, the clinical and/or subclinical relevance of periprocedural DW-MRI lesions requires further evaluation ${ }^{32}$.

\section{Conclusions}

Data from the present real-life multicentre study demonstrate the 30-day efficacy and safety of CAS using exclusively the novel MicroNet-covered CGuard Embolic Prevention System, with a significant reduction of post-procedural adverse neurologic events in a predominantly asymptomatic cohort.

\section{Impact on daily practice}

The IRON-Guard registry represents the largest real-world study on patients submitted for CAS with the new mesh-covered CGuard Embolic Prevention System (EPS). The CGuard EPS has proved safe and effective in lowering periprocedural and post-procedural neurological complications. Thirty-day follow-up results confirm its role in effectively preventing brain embolic events. The low rate of ipsilateral subclinical brain lesions detected by DW-MRI shows the importance of keeping the pore/cell size to a minimum in order to minimise brain damage. Based on the present experience, CGuard stent deployment might also be considered in high-risk composition carotid plaques.

\section{Conflict of interest statement}

The authors have no conflicts of interest to declare.

\section{References}

1. Mas JL, Trinquart L, Leys D, Albucher JF, Rousseau H, Viguier A, Bossavy JP, Denis B, Piquet P, Garnier P, Viader F, Touzé E, Julia P, Giroud M, Krause D, Hosseini H, Becquemin JP, Hinzelin G, Houdart E, Hénon H, Neau JP, Bracard S, Onnient Y, Padovani R, Chatellier G; EVA-3S investigators. Endarterectomy Versus Angioplasty in Patients with Symptomatic Severe Carotid Stenosis (EVA-3S) trial: results up to 4 years from a randomised, multicentre trial. Lancet Neurol. 2008;7:885-92.

2. Pratesi C, Dorigo W, Innocenti AA, Azas L, Barbanti E, Lombardi R, Pratesi G, Pulli R. Reducing the risk of intraoperative neurological complications during carotid endarterectomy with early distal control of the internal carotid artery. Eur J Vasc Endovasc Surg. 2004;28:670-3.

3. Cassese S, Ndrepepa G, King LA, Nerad M, Schunkert H, Kastrati A, Ott I, Fusaro M. Proximal occlusion versus distal filter for cerebral protection during carotid stenting: updated meta-analysis of randomised and observational MRI studies. EuroIntervention. 2015;11:238-46.

4. Kwolek CJ, Jaff MR, Leal JI, Hopkins LN, Shah RM, Hanover TM, Macdonald S, Cambria RP. Results of the ROADSTER multicenter trial of transcarotid stenting with dynamic flow reversal. J Vasc Surg. 2015;62:1227-34.

5. Al-Mubarak N, Roubin GS, Vitek JJ, Iyer SS, New G, Leon MB. Effect of the distal-balloon protection system on microembolization during carotid stenting. Circulation. 2001;104: 1999-2002.

6. Musialek P, Mazurek A, Trystula M, Borratynska A, LesniakSobelga A, Urbanczyk M, Banys RP, Brzychczy A, Zajdel W, Partyka L, Zmudka K, Podolec P. Novel PARADIGM in carotid revascularisation: Prospective evaluation of All-comer peRcutaneous cArotiD revascularisation in symptomatic and Increased-risk asymptomatic carotid artery stenosis using CGuard ${ }^{\mathrm{TM}}$ MicroNetcovered embolic prevention stent system. EuroIntervention. 2016; 12:e658-70.

7. Swier VJ, Tang L, Krueger KD, Radwan MM, Del Core MG, Agrawal DK. Coronary Injury Score Correlates with Proliferating Cells and Alpha-Smooth Muscle Actin Expression in Stented Porcine Coronary Arteries. PLoS One. 2015;10:e138539.

8. Fairman R, Gray WA, Scicli AP, Wilburn O, Verta P, Atkinson R, Yadav JS, Wholey M, Hopkins LN, Raabe R, Barnwell S, Green R; CAPTURE Trial Collaborators. The CAPTURE registry: analysis of strokes resulting from carotid artery stenting in the post approval setting: timing, location, severity, and type. Ann Surg. 2007;246:551-6.

9. de Donato G, Setacci F, Sirignano P, Galzerano G, Cappelli A, Setacci C. Optical coherence tomography after carotid stenting: rate of stent malapposition, plaque prolapse and fibrous cap rupture according to stent design. Eur J Vasc Endovasc Surg. 2013;45: 579-87.

10. Liu R, Jiang Y, Xiong Y, Li M, Ma M, Zhu W, Yin Q, Li W, Xu G, Liu X. An Optical Coherence Tomography Assessment of Stent Strut Apposition Based on the Presence of Lipid-Rich Plaque in the Carotid Artery. J Endovasc Ther. 2015;22:942-9.

11. Schofer J, Arendt M, Tübler T, Sandstede J, Schlüter M. Late cerebral embolization after emboli-protected carotid artery stenting assessed by sequential diffusion-weighted magnetic resonance imaging. JACC Cardiovasc Interv. 2008;1:571-7.

12. Nerla R, Castriota F, Micari A, Sbarzaglia P, Secco GG, Ruffino MA, de Donato G, Setacci C, Cremonesi A. Carotid artery stenting with a new-generation double-mesh stent in three highvolume Italian centres: clinical results of a multidisciplinary approach. EuroIntervention. 2016;12:e677-83.

13. Schofer J, Musiałek P, Bijuklic K, Kolvenbach R, Trystula M, Siudak Z, Sievert H. A Prospective, Multicenter Study of a Novel 
Mesh-Covered Carotid Stent: The CGuard CARENET Trial (Carotid Embolic Protection Using MicroNet). JACC Cardiovasc Interv. 2015;8:1229-1234.

14. Setacci C, Speziale F, De Donato G, Sirignano P, Setacci F, Capoccia L, Galzerano G, Mansour W; IRON-Guard Study Group. Physician-initiated prospective Italian Registry of carotid stenting with the C-Guard mesh-stent: the IRON-Guard registry. Rationale and design. J Cardiovasc Surg (Torino). 2015;56: 787-91.

15. North American Symptomatic Carotid Endarterectomy Trial Collaborators, Barnett HJM, Taylor DW, Haynes RB, Sackett DL, Peerless SJ, Ferguson GG, Fox AJ, Rankin RN, Hachinski VC, Wiebers DO, Eliasziw M. Beneficial effect of carotid endarterectomy in symptomatic patients with high-grade carotid stenosis. N Engl J Med. 1991;325:445-53.

16. Fischer U, Baumgartner A, Arnold M, Nedeltchev K, Gralla J, De Marchis GM, Kappeler L, Mono ML, Brekenfeld C, Schroth G, Mattle HP. What is a minor stroke? Stroke. 2010;41:661-6.

17. Tegos TJ, Stavropoulos P, Sabetai MM, Khodabakhsh P, Sassano A, Nicolaides AN. Determinants of carotid plaque instability: echoicity versus heterogeneity. Eur J Vasc Endovasc Surg. 2001;22:22-30.

18. Virmani R, Burke AP, Farb A, Kolodgie FD. Pathology of the vulnerable plaque. J Am Coll Cardiol. 2006;47:C13-8.

19. Redgrave JN, Gallagher P, Lovett JK, Rothwell PM. Critical cap thickness and rupture in symptomatic carotid plaques: the oxford plaque study. Stroke. 2008;39:1722-9.

20. Yadav JS, Wholey MH, Kuntz RE, Fayad P, Katzen BT, Mishkel GJ, Bajwa TK, Whitlow P, Strickman NE, Jaff MR, Popma JJ, Snead DB, Cutlip DE, Firth BG, Ouriel K; Stenting and Angioplasty with Protection in Patients at High Risk for Endarterectomy Investigators. Protected carotid-artery stenting versus endarterectomy in high-risk patients. $N$ Engl J Med. 2004; 351:1493-501.

21. Lam RC, Lin SC, DeRubertis B, Hynecek R, Kent KC, Faries PL. The impact of increasing age on anatomic factors affecting carotid angioplasty and stenting. J Vasc Surg. 2007;45: 875-80.

22. Rautaharju PM, MacInnis PJ, Warren JW, Wolf HK, Rykers PM, Calhoun HP. Methodology of ECG interpretation in the Dalhousie Program: NOVACODE ECG classification procedures for clinical trials and population health surveys. Methods Inf Med. 1990;29:362-74.
23. Cremonesi A, Setacci C, Bignamini A, Bolognese L, Briganti F, Di Sciascio G, Inzitari D, Lanza G, Lupattelli L, Mangiafico S, Pratesi C, Reimers B, Ricci S, de Donato G, Ugolotti U, Zaninelli A, Gensini GF. Carotid artery stenting: first consensus document of the ICCS-SPREAD Joint Committee. Stroke. 2006;37:2400-9.

24. Bosiers M, Deloose K, Torsello G, Scheinert D, Maene L, Peeters P, Müller-Hülsbeck S, Sievert H, Langhoff R, Bosiers M, Setacci C. The CLEAR-ROAD study: evaluation of a new dual layer micromesh stent system for the carotid artery. EuroIntervention. 2016;12:e671-6.

25. Nicolaides AN, Kakkos SK, Kyriacou E, Griffin M, Sabetai M, Thomas DJ, Tegos T, Geroulakos G, Labropoulos N, Doré CJ, Morris TP, Naylor R, Abbott AL; Asymptomatic Carotid Stenosis and Risk of Stroke (ACSRS) Study Group. Asymptomatic internal carotid artery stenosis and cerebrovascular risk stratification. J Vasc Surg. 2010;52:1486-1496.

26. Bosiers M, de Donato G, Deloose K, Verbist J, Peeters P, Castriota F, Cremonesi A, Setacci C. Does free cell area influence the outcome in carotid artery stenting? Eur J Vasc Endovasc Surg. 2007;33:135-41.

27. Schönholz C, Yamada R, Montgomery W, Brothers T, Guimaraes M. First-in-man implantation of a new hybrid carotid stent to prevent periprocedural neurological events during carotid artery stenting. J Endovasc Ther. 2014;21:601-4.

28. Rapp JH, Pan XM, Sharp FR, Shah DM, Wille GA, Velez PM, Troyer A, Higashida RT, Saloner D. Atheroemboli to the brain: size threshold for causing acute neuronal cell death. J Vasc Surg. 2000;32:68-76.

29. Musialek P, Hopf-Jensen S. Commentary: Carotid Artery Revascularization for Stroke Prevention: A New Era. J Endovasc Ther. 2017;24:138-148.

30. Pinter L, Ribo M, Loh C, Lane B, Roberts T, Chou TM, Kolvenbach RR. Safety and feasibility of a novel transcervical access neuroprotection system for carotid artery stenting in the PROOF Study. J Vasc Surg. 2011;54:1317-23.

31. Parodi JC. The ideal carotid stent? Time will tell. J Endovasc Ther. 2014;21:605-6.

32. Stabile E, Giugliano G, Cremonesi A, Bosiers M, Reimers B, Setacci C, Cao P, Schmidt A, Sievert H, Peeters P, Nikas D, Sannino A, de Donato G, Parlani G, Castriota F, Hornung M, Rubino P, Esposito G, Tesorio T. Impact on outcome of different types of carotid stent: results from the European Registry of Carotid Artery Stenting. EuroIntervention. 2016;12:e265-70. 